\title{
UMA NOVA PERSPECTIVA SOBRE A QUEDA DO IMPÉRIO E O COMEÇO DA REPÚBLICA (*).
}

\author{
JUNE E. HAHNER \\ State University of New York at Albany.
}

Em novembro de 1889 , elementos das forças armadas sediadas no Rio de Janeiro substituiram oficialmente a monarquia brasileira. As análises desses acontecimentos incluem sempre o descontentamento do Exército como um dos principais fatores da queda do Império, bem como a decepção dos lavradores decorrente da abolição da escravatura sem compensação, a gradativa aceitação da inevitabilidade de uma república pela elite política brasileira, e a "Questão Religiosa", ou seja, o conflito entre o secularismo e o ultramontonismo na década de 1870. Muitos dos mais antigos estudos desses acontecimentos, tal como o de Oliveira Vianna, salientam as forças armadas como o principal fator da queda do Império. Entretanto, alguns trabalhos mais recentes, por exemplo o de José Maria Bello, relegam os oficiais a um papel muito menos importante (1). Neste artigo, ambos os pontos de vista serão considerados e a composição e as atividades das forças armadas serão examinadas.

Alem de acentuar o papel das forças armadas na queda da monarquia, Oliveira Vianna as encara como um agrupamento passivo, estimulado e virtualmente dirigido por políticos da oposição, muitos dos quais eram republicanos. Este

"systema de exploração das classes armadas, concebido, organizado e montado pelos politicos do Império é que haveria de ser,

${ }^{*}$ ). - Agradeço ao Dr. Francisco Glycério Neto pelo auxílio prestado na tradução do texto inglês para 0 português.

(1). - F. J. Oliveira Vianna, $O$ occaso do Império. São Paulo; 1925 : José Maria Bello, História da República (1889-1954), 4a. edição, São Paulo. 1959. 
dentro em pouco tempo, o ariete com que iriam desmantelar, involuntariamente talvez, o proprio Império" (2).

Heitor Lyra, em recente trabalho, ressaltando a importância das forças armadas na queda da monarquia, pretende tambem que os políticos dissidentes

\footnotetext{
"desviaram as classes armadas de suas obrigações militares para joga-las contra as instituições vigentes" (3).
}

Os adeptos do antigo regime monárquico acharam difícil responsabilizar a própria monarquia pelas condições que a levaram à sua substituição pela república, e salientaram a atuação das forças armadas, alegando que os oficiais foram incitados por políticos oposicionistas.

E verdade que muitos republicanos contavam fazer conversões entre os oficiais, da mesma forma que entre outras classes da nação. Numerosos dentre os jovens oficiais se tornaram fervorosos republicanos. Alguns republicanos e outros adversários dos diferentes ministérios monarquistas defenderam os oficiais durante a "Questão Militar". Diversos políticos de oposição chegaram a fazer uso dos receios do Exército, especialmente o medo de que o Exército pudesse ser substancialmente reduzido em seu efetivo e importância e que uma forte milícia pudesse surgir como força contrária (4).

A questão de quando, exatamente, o Marechal Deodoro da Fonseca foi convertido às convicções republicanas tem atraido a atenção de muitos escritores. Entretanto, a data exata desse fato, se isso realmente teve lugar, é difícil determinar. Certamente Deodoro não era republicano alguns meses antes da derrubada do Império. Em 1888 ele escreveu a um de seus sobrinhos, aluno da Escola Militar e republicano, para não acompanhar aqueles

"tolos ou malucos" ou meter-se "em questões republicanas", visto que "República no Brasil é coisa impossivel, porque terá verdadeira desgraça".

(2). - Oliveira Vianna, opus cit., 135.

(3). - Heitor Lyra, História da queda do Império, 2 vols. São Paulo, 1964, II, 132.

(4). - Vide editoriais no $O$ Republicano (Rio de Janeiro), A Federação (Porto Alegre), A Denúncia (Porto Alegre), e Diário de Notícias e $O$ País no Rio de Janeiro, em 1889. Cf. George C. A. Boehrer, Da monarquia d república. História do Partido Republicano do Brasil (1870-1889). Trad. Berenice Xavier. (Rio de Janeiro, 1954), 291-300. 
Enquanto isso era "mau" com a Monarquia, muito "pior sem ella", porque o Brasil continuava sem preparo e sem educação para uma república (5). Quintino Bocaiúva que, como um dos líderes do Partido Republicano tentava criar a hostilidade dos militares para com o governo imperial, tinha pouca confiança em Deodoro já em 1889. Em carta a um amigo íntimo, relatando os distúrbios do movimento republicano, declarava que a então recente

\author{
"morte do Madureira foi para nós um desastre e com o Deo- \\ doro não podemos contar" (6).
}

O Exército, como um todo, não era simples instrumento de ambições dos civis para ser usado por hábeis políticos para seus próprios objetivos. Alguns líderes da oposição tinham soprado as chamas do descontentamento dos militares, mas eles não tinham ateado o fogo. As forças armadas não eram dócil instrumento de ninguem; pelo contrário, mas constituíam, por si só, uma potência. Alguns republicanos realmente desejavam utilizar o descontentamento dos militares e outros esperavam que os oficiais se tornassem aliados subordinados, mas republicanos como Joaquim Saldanha Marinho e Cristiano Benedito Ottoni ficaram desiludidos depois do 15 de novembro, quando os oficiais chegaram no poder.

Durante a "Questão Militar" da década de 1880, Joaquim Saldanha Marinho alem de ter fornecido aos oficiais uma justificação teórica para seus atos como tinha muitas vezes defendido suas insubordinações. Na Revista Federal, jornal republicano, citou vários precedentes históricos e leis para demonstrar que os oficiais possuíam o necessário

\footnotetext{
"critério de conhecer da legalidade das ordens para executal-as", e que "Deixar de cumprir uma ordem illegal não é acto revolucionario" (7).
}

Mas, em seguida à implantação da República, Saldanha Marinho expressou seu desapontamento e desilusão com o novo regime. Ele repetidamente demonstrou sua preocupação pelos "direitos civis" violados pelo regime dominado pelos militares, alegando que

(5). - Deodoro a Clodoaldo da Fonseca, Rio de Janeiro, 30 de setembro de 1888 e 16 de outubro de 1888, Coleção Clodoaldo da Fonseca, do $\mathrm{D}$ : . Roberto Piragibe da Fonseca, Rio de Janeiro.

(6) . - Quintino Bocaiúva a Gabriel Cruz, Rio de Janeiro, 19 de fevereiro de 1889, Arquivo do Museu Histórico Nacional, sem número.

(7). - Revista Federal, I, no 6 (31 de outubro de 1886), 2-3. 


\begin{abstract}
"republica como esta não é certamente aquella pella qual affrontei as iras do imperador" (8).
\end{abstract}

Cristiano Benedito Ottoni nunca encorajou ou aprovou a participação dos militares na política, ao contrário de Saldanha Marinho. Ottoni parece ter pensado que o Exército seria apenas o agente imediato para a proclamação da República em 1889 , chamado no último minuto pelos civis que deveriam permanecer na chefia, como ocorrera com a deposição de D. Pedro I em 1831, e à qual Ottoni assistiu. O predomínio dos militares no governo e os perigos para os "direitos civis" que ele testemunhava sob a jovem república causavam-lhe grande apreensão para o futuro (9).

Em oposição a Oliveira Vianna, historiadores mais recentes, como José Maria Bello, reduzem o papel das forças armadas na derrubada da Monarquia. Bello entende que sua ação provou ser decisiva porque o Império estava à beira do colapso;

"já eram tão fracas as raízes do Império, que qualquer incidente mais grave as extirparia. No fundo, foram sempre republicanos, embora incertos ou confusos os sentimentos de boa parte das elites brasileiras" (10).

Bello reflete, amplamente, as opiniões de Felisbello Freire, um republicano e testemunha dos acontecimentos de novembro de 1889 , o qual entende que os republicanos civis, através de sua propaganda

"se tinham infiltrado no espírito público" (11).

Durante esse período, entretanto, as forças armadas foram fator político vital, visto que exerceram decisivo controle no Brasil por vários anos depois da queda do Império. O novo governo republicano estava dominado por oficiais que, em crescente número, preencheram muitas das que, anteriormente, eram consideradas posições civis, desde ministros de estado e governadores estaduais até funções no sistema telegráfico, nas ferrovias, no corpo diplomático e consular, nas escolas

(8). - Sessão de 22 de junho de 1892, Congresso Nacional, Annaes do Senado Federal. Segunda sessão da primeira legislatura, II, 35.

(9) . - Cristiano Benedicto Ottoni, $O$ advento da República no Brasil. (Rio de Janeiro, 1890), 82-84, 107-108, 124-130.

(10). - Bello, História da República, 4.

(11). - Felisbello Firmo de Oliveira Freire, História constitucional da República dos Estados Unidos do Brasil, (Rio de Janeiro, 1894-5), II, 5. 
públicas e nos matadouros (12). Embora numerosos civis participassem do governo provisório republicano, foram incapazes de exercer influência decisiva em assuntos de importância para os oficiais. Como o próprio Felisbelo Freire o admitia,

"O poder estava de facto em suas mãos. Um civil investido de auctoridade, ou submettia-se á orientação que lhe era traçada pelo meio militar em que vivia, ou retirava-se do cargo, voluntariamente ou destituido" (13).

As forças armadas, portanto, eram um poder antes e depois da queda do Império, poder que não podia ser ignorado nem deve ser subestimado. Embora fossem um dos principais fatores que conduziram à queda da Monarquia, talvez não seja possivel determinar o exato valor relativo aos demais fatores. Por outro lado, seria mais interessante examinar a composição das forças armadas que permitiram esse tipo de atividade tanto antes como depois da derrubada da Monarquia.

Essas forças organizadas de homens armados não eram um corpo unido, monolítico, porem uma força armada fortemente dividida. As dissenções que existiam dentro dela foram cruciais para suas atividades políticas, facilitando-lhes o envolvimento político, afetando seu comportamento quando no poder depois de 1889 e facilitando seu afastamento do poder em 1894 .

Enquanto os oficiais das forças armadas brasileiras tinham plena consciência de si próprios como militares, não tinham eles sua própria ideologia ou programa político. Nas palavras do antigo republicano C. B. Ottoni, na década de 1880

"não sustentavam elles idéa ou principio politico, não aspiravam a reforma alguma de interesse geral" (14).

Enquanto alguns oficiais defendiam certos programas políticos, tais como a abolição da escravatura, refletindo posições e argumentos civis, estavam eles tão desunidos e superficiais a respeito das reais necessidades e problemas da nação como muitos dos civis. Seu senso de honra e de solidariedade de classe funcionou mais efetivamente como um fator de unificação quando acreditaram estar sendo atacados por um governo distante e antipático, como, por exemplo, durante a "Questão

(12). - Jornal do Comércio, 25 de junho de 1893, 1; cf. Felisbello Firmo de Oliveira Freire, História da revolta de 6 de setembro de 1893, (Rio de Janeiro, 1896), 75 .

(13). - Freire, História constitucional da república, II, 81.

(14). - Ottoni, $O$ advento da República no Brasil, 84. 
Militar". Esta questão é constantemente ressaltada em muitos das mais antigas interpretações do ocaso do Império, mas seu significado é mal compreendido. Esses incidentes demonstram que a unidade militar existia somente em matéria de honra e questões de serviço.

Conquanto na opinião de alguns escritores essa série de incidentes militares tenha tido sua origem nas modificações resultantes da Guerra do Paraguai (15) é dificil estabelecer um elo direto entre essa Guerra e os incidentes posteriores. A Guerra do Paraguai terminou em 1870 e o primeiro incidente da "Questão Militar" não explodiu senão em 1879 , tendo o segundo incidente ocorrido em 1883. Este lapso de tempo é demasiado para se dar crédito total às afirmações de alguns oficiais tinham mais tempo disponivel para tomar parte na política. Exército brasileiro e o levou a enfrentar diretamente o governo (16). Mesmo que os oficiais não tivessem aprendido lições diretas no Prata, a Guerra deixou as bases para um Exército relativamente inativo, cujos oficiais tinham mais tempo disponivel para tomar parte na política. Eles se ressentiram da constante redução dos efetivos depois do fim da Guerra, tanto pelos seus soldos relativamente baixos, como pelas magras vantagens percebidas no Exército (17).

A profundidade do ressentimento dos oficiais nessas condições é claramente demonstrada pelo violento aumento dos quadros e das vantagens do Exército declarado pelo Governo Provisório, dominado por militares, quase imediatamente após a queda da Monarquia. De um efetivo aproximado de 23.000 homens no fim da Guerra do Paraguai, o Exército fora reduzido a $15.000 \mathrm{em} 1880$, oscilando então entre 11.000 e 13.000 durante muitos anos. Em 1888, o Exército era realmente de 11.748 homens. Mas, uma vez implantada a República, o Exército se expandia rapidamente. Um mês depois da organização do novo regime, o efetivo da cavalaria, artilharia e corpos de infantaria era aumentado. Mais duas unidades de artilharia foram adicionadas às oito normais, e mais seis batalhões de infantaria aos trinta já existentes. Logo as forças de terra incluiam legalmente mais de 24.000 homens e naquela época contavam uns 20.000. O soldo dos oficiais foi aumen-

(15). - Oliveira Vianna, $O$ ocaso do Império, 1936; Ottoni, $O$ advento da República no Brasil, 80; Freire, História constitucional da República, I, 191 .

(16) . - Demétrio Seixas, $O$ golpe d'estado de 15 de novembro (Ao exército e à armada) (Porto-Alegre, 1890), 171; cf. Jacques Ourique, "A revolução de 15 de novembro", in Jornal do Comércio, 4 de janeiro de 1890, 2.

(17). - Até os monarquistas mais anti-militaristas, como Eduardo Prado, concordavam que o exército estava mal pago, instruído e organizado. (pseud. Frederico de S.), Fastos da dictadura militar no Brazil. 3a. ed. Lisboa, 189u), 5-6. 
tado talvez de 40 a $50 \%$, em poucos meses depois da derrubada do Império e o orçamento do Ministério da Guerra continuou a subir (18).

Durante o Império, os oficiais tinham queixas específicas e aspirações concernentes à sua carreira, mas não um programa político, definido e coeso para impo-lo à nação. Eles eram basicamente reclamantes sem programas.

A singular situação existente durante os últimos anos da década de 1880 foi mais propícia à participação dos militares na política porque faltava forte liderança no governo. Os partidos políticos do Império não se diferenciavam muito um do outro por-seus programas e capacidades. Essa situação, que se deteriorava rapidamente, auxiliou a atividade política paralela dos militares e deu maior força ao descontentamento dos elementos-chaves das forças armadas.

A distribuição de contingentes das forças armadas contribuiu para o sucesso do movimento de tropas no Rio de Janeiro em novembro de 1889. A existência de uma grande guarnição do Exército na capital facilitou a participação individual de oficiais nas disputas políticas, no centro da cidade, a uma distância de um simples percurso de bonde (19) . Civis e oficiais dissidentes combinaram-se facilmente, e a propaganda de oposição era dirigida a um grupo menor. Não era preciso influir na totalidade do Exército, apenas na guarnição do Rio de Janeiro. Desde que ao Império faltava o apôio total da minoria politicamente atuante, nenhum outro segmento das forças armadas contestaria os acontecimentos que ocorreram na Capital em novembro de 1889 .

A existência de facções do poder que estavam centralizadas em apenas alguns indivíduoos afetou tambem o curso daqueles acontecimentos. Na década de 1880, o mais popular oficial no Exército brasileiro era Deodoro da Fonseca que, na palavra de Campos Sales, era

"amado até a idolatria no Exército.... ninguém dispunha, como elle, de tanto poder de fascinação para attrahir e dirigir as classes militares em um movimento contra a monarchia" (20).

(18). - Brasil, Ministério da Guerra, Relatório, 1888, Anexos, 3; João Batista Magalhães, $A$ evolução militar do Brasil (Anotações para a históita) . (Rio de Janeiro, 1958, 312-19; Gustavo Barroso, História militar do Brasil, (São Paulo, 1935), 83; Theodorico Lopes e Gentil Tôrres, Ministros da guerra do Brasil (1808-1950), 4a. edição, (Rio de Janeiro, 1950), 30, Amador Pereira Gomes Nogueira Cobra, Brios de gente armada (Páginas republicanas na história do Brasil). (São Paulo, 1924), 180.

(19). - Em 1889, dos 13.152 homens do exército, 1.911 estavam no Rio de Janeiro. Brazil, Ministério da Guerra, Relatório, 1889, Annexos, 12. (20) . - Manuel Ferraz Campos Salles, Da propaganda à presidência, São Paulo, 1908, 54. 
Depois que Deodoro foi transferido de volta ao Rio de Janeiro em setembro de 1889 , tornou-se mais facil incitar um movimento contra o Gabinete Ouro Preto. A popularidade de Deodoro tambem auxiliou a manter unidas as forças armadas temporariamente, e faze-las aceitar os acontecimentos ocorridos no Rio de Janeiro.

Em seguida à implantação de uma República, desapareceu a superficial união das forças armadas, conseguida durante a "Questão Militar", e as divergências básicas surgiram. Um governo civil, supostamente hostil, não mais serviria como base para essa união superficial.

Embora o regime republicano provisório fosse um governo predominantemente militar, nem todos os grupos militares estavam igualmente representados. Alguns oficiais se achavam muito mais afastados do que outros da sede do governo, agravando-se assim ciumes e ambições. Os oficiais no poder tinham que dirigir o país e tomar decisões que afetavam seus camaradas de armas e isso deu maiores oportunidades para antagonizar grupos dentro das forças armadas. As hostilidades anteriormente desfechadas num governo civil deveriam ser dirigidas contra um regime dominado por militares e este regime teria que enfrentar uma série de incidentes militares e movimentos de oposição.

As divergências militares baseadas em lealdade e fidelidade pessoal a certos líderes continuavam a afetar a atividade política dos oficiais. A perda de popularidade de Deodoro fora da infantaria, enquanto Chefe do Estado, facilitou sua retirada em novembro de 1891, devido a uma temporária coalisão de oficiais leais ao Marechal Floriano Peixoto, General José Simeão e Almirante Custódio José de Melo (21). A despeito dos esforços de alguns dos seus companheiros, logo no ano seguinte, Deodoro não pode retomar o poder (22).

Outras divergências militares giravam em torno do antagonismo entre os oficiais veteranos e os novos, especialmente os jovens formados pela Escola Militar do Rio de Janeiro. Sob a direção de professores como o Tenente-Coronel Benjamin Constant Botelho de Magalhães, muitos dos cadetes do Exército imperial se tornaram fervorosos republicanos. Falava-se que esses jovens oficiais representavam a nas-

(21). - José Carlos de Carvalho, O livro da minha vida. Na guerra, na paz e nas revoluções (1847-1910). Rio de Janeiro, 1912, 100-119; Serzedello Corrêa, 1. J. Uma Figura da República. Páginas do passado. 2a. edição, Rio de Janeiro, 1959, 44-46; Custódio José de Melo, $O$ governo provisório e a revolução de 1893, São Paulo, 1938, I, 18, 37-39: Gazeta de Notícias, 25 de novembro de 1891,1 .

(22). - Carvalho J. C. de, O livro da minha vida, 171-180; Dunshee de Abranches, ed. O golpe de estado. Atas e atos do governo Lucena, Rio de Janeiro, 1954, 133-139. F. G., O Dia, 10, 11, e 12 de abril de 1901 . 
cente classe média e eram, portanto, mais predispostos à mudança política. Alguns graduados da Escola Militar haviam descrito esta instituição como uma Meca para pobres e ambiciosos rapazes em busca de educação adiantada (23). Dado o fato de possuirmos bons dados biográficos apenas sobre uns poucos oficiais das mais altas patentes, torna-se muito dificil concretizar as pretensões de escritores como Nelson Werneck Sodré ou San Tiago Dantas quanto à existência e natureza de laços muito íntimos entre o Exército e a nascente classe média (24). Em vez disso, os dados existentes indicam uma completa inconsciência da condição de classe média no Exército, porque faltou tal consciência no país inteiro. À classe média faltava força política decisiva, tanto quanto coesão ideológica, de acordo com Nícia Villela Luz (25) . Certamente, o corpo de oficiais do Exército, como um todo, não poderia ter representado a classe média ou tomado qualquer posição refletindo opiniões coerentes de classe média, visto que nem o Exército, nem a classe média estavam unidos. Aqueles oficiais mais moços não tinham o necessário poder militar para determinarem por eles próprios o destino da Monarquia ou da República. Somente se eles representassem as mais amplas correntes nas forças armadas, poderiam seus pronunciamentos trazer consigo grande peso.

As discussões do Clube Militar, fundado em 1887, no auge da "Questão Militar", para dar aos oficiais do Exército uma tribuna para exporem seus agravos, ilustram as opiniões de muitos daqueles jovens oficiais. Alguns se acharam responsáveis pela sorte da República, desde que tinham, entusiasticamente, aceitado a sua proclamação como sua própria realização. Justificavam seu comportamento durante os primeiros dias da República dizendo que

"a classe militar passa por ter a responsabilidade de tudo o que se tem dado em nossa patria, desde 15 de Novembro" (26).

Logo que esta crença fosse alem da retórica poderia facilitar sua participação no processo político.

(23) . - Augusto Ximeno de Villeroy, Benjamin Constant e a política republicana, Rio de Janeiro, 1928, 2; Vicente Licínio Cardoso, "Benjamin Constant", A Margem da história da República, Ideas, crenças e affirmaçōes, Rio de Janeiro, 1924, 296.

(24). - Francisco Clementino de San Tiago Dantas, Dois momentos de Rui Barbosa. Rio de Janeiro, 1949, 17-19; Nelson Werneck Sodré, Formação histórica do Brasil, São Paulo, 1962, 270-74.

(25). - Nícia Villela Luz, "O papel da classes médias brasileiras no movimento republicano", Revista de História, $\mathrm{n}^{\circ} 57$ (janeiro-março de 1964), 13-27.

(26). - Atas do Clube Militar, sessão de 5 de novembro de 1890. 
Conquanto os jovens oficiais não fossem tão poderoso fator, como acreditam alguns escritores, eles se opunham a outro grupo de oficiais $e$ isso aumentou o tumulto do período. Suas atividades, opiniões e formação provocaram a hostilidade de muitos oficiais veteranos politicamente ativos. Um destes Jacques Ourique, que tinha longamente militado na política, declarou que, durante os últimos quinze anos antes da derrubada da Monarquia, as escolas militares tinham sido transformadas em Instituições

"de fazer bons soldados em fabricas de doutores de camarilha, mais aptos em seu doentio mysticismo altruista para as concepçoses abstractas de republicas platonicas do que para a rude tarefa de commandar batalhōes ou companhias" (27).

Muitos dos oficiais mais velhos não haviam cursado as escolas militares ou passado pelas mãos de Benjamin Constant e outros professores positivistas, e desdenhavam

\footnotetext{
"essa bacharelice positivista" e "essa semi-ignorancia pretenciosa e balofa" (28).
}

Essas diferenças entre os mais jovens e os mais velhos oficiais ajudavam a aumentar suas desavenças políticas, contribuindo para as atividades militares do período. Os oficiais veteranos do Exército, especialmente, ressentiam-se de qualquer crítica às suas posições politicas e às manifestações dos jovens oficiais, como ocorreu em 1892, quando o Clube Militar expulsou os treze generais e almirantes que, sem sucesso, solicitaram ao Marechal Floriano Peixoto a convocação da eleição presidencial. O general Honorato Caldas, um veterano da "Questão Militar", resumiu esses resentimentos quando acusou os jovens oficiais do Clube Militar de serem

"os discipulos castigando os mestres... a major e ao capitão é licito interpretar a Constituição, aos generaes não!" (29).

Durante os primeiros anos da República, as tradicionais rivalidades e litígios entre o Exército e a Marinha foram intensificados. Os oficiais de Marinha entraram, então, na arena política, pois consideraram ameaçados os seus interesses de classe. Tomaram parte em movimentos contra o governo dominado pelo Exército, culminando com a

(27). - Jacques Ourique, Correio da Tarde, 31 de dezembro de 1895, 1 .

(28). - Idem, ibidem.

(29) - Honorato Candido Ferreira Caldas (pseud. Kleber), A legalidade do 23 de novembro, Rio de Janeiro, 1892, 47. 
Revolta da Armada de 1893-94. Os oficiais da Marinha acreditavam que o Marechal Floriano Peixoto estava favorecendo o Exército em vencimentos e vantagens e subordinando a Marinha. Assim como vários oficiais do Exército, antes do 15 de novembro de 1889, os oficiais da Marinha sentiram que seu corpo havia sido desdenhado e mal apreciado e sua honra, atingida.

$\mathrm{Na}$ palavra do Almirante Custódio de Melo, o lider dos insurgentes navais, a rebelião desencadeou-se

"para restaurar o poder da Lei, da ordem e da paz" (30).

Mas a Revolta da Armada não conseguiu apôio algum da população civil. Somente alguns irredutíveis monarquistas, que continuavam a procurar, sem sucesso, facções militares para derrubar a República, estavam interessados no exito da revolta. Mas os sentimentos monarquistas dentro da armada eram extremamente fracos. O único monarquista prestigioso entre os principais oficiais da armada era o Almirante Luiz Felipe Saldanha da Gama. Seu manifesto pugnando por um plebiscito sobre a forma do governo do Brasil foi muito mal recebido pelos brasileiros, demonstrando, desse modo, ser insustentavel uma posição monarquista (31). Os rebeldes navais receberam somente algum auxílio monetário dos monarquistas, e mesmo esse grandemente exagerado (32). Essa revolta é mais bem compreendida à luz da rivalidade Exército-Marinha, do que como tentativa monarquista.

Dentro da própria Marinha existiam divergências, baseadas primariamente em sentimentos de lealdade pessoal. A falta de cooperação entre os Almirantes Eduardo Wandenkolk, Custódio de Melo e Saldanha da Gama e seus companheiros antes e depois do começo da revolta foi um fator-chave do fracasso da mesma. Em 1893, a Marinha não tinha líder destacado que pudesse promover uma união provisória, como tinha ocorrido com Deodoro da Fonseca e o Exército em 1889.

As dissenções dentro do Exército e da Marinha e as rivalidades entre os dois corpos, que a Revolta da Armada demonstrou, tiveram

(30). - Manifesto do Almirante Melo, Jornal do Comércio, 7 de setembro de $1893,1$.

(31). - Manifesto de Saldanha da Gama, 7 de dezembro de 1893. Dunshee de Abranches, $A$ revolta da armada e a revolução rio-grandense, Rio de Janeiro, 1914, I, 11-13.

(32). - Notas de um revoltoso, (Rio de Janeiro, 1895), 135-39. 46-50; Melo, $O$ governo provisório, II, 34-36; 300-301; Dunshee de Abranches, $A$ revolta da armada, I, 29-30, 68-69; II, 25-29; Saldanha a Carlos Landares, Montevideo, 9 de outubro de 1894, Arquivo do Serviço Geral da Marinha, Caixa 70; Conde de Leopoldino a Rui Barbosa, Lisboa, 17 de dezembro de 1893 e 8 de janeiro de 1894. Casa de Rui Barbosa. 
outros efeitos. Por meio do judicioso uso dessas divergências, um grupo coeso de civis, composto principalmente dos representantes do economicamente poderoso Estado de São Paulo, tirou o controle imediato das mãos dos oficiais. Os Paulistas se opunham ao predomínio dos militares, visto que a instabilidade dos governos militares punha em perigo o crescimento econômico, a prosperidade e a autonomia do seu Estado. Em vez de atacar diretamente os oficiais no governo militar chefiado pelo Marechal Floriano, eles cooperavam e celebravam acordo, quando necessário. Durante a Revolta da Armada, os Paulistas prestaram auxílio decisivo ao regime de Floriano por meio da milícia estadual. Em 1894, eles conseguiram eleger Prudente de Morais, um dos mais anti-militaristas dos seus colegas, para presidência (33).

As divergências existentes no seio das forças armadas brasileiras tornaram possivel determinar a natureza da participação política dos oficiais e até levar ao fim do controle militar ostensivo. A participação dos oficiais na queda da Monarquia foi apenas uma etapa nesse processo, e é insatisfatório e improdutivo tentar-se separar os acontecimentos de 15 de novembro de 1889 dos outros atos praticados pelos oficiais. As forças armadas, com todas suas divergências, constituiram o maior poder no Brasil, antes e depois da queda da Monarquia. Um poder capaz de derrubar o vacilante Império e dominar durante os primeiros anos da República.

(33). - June E. Hahner, "The Paulistas Rise to Power. A Civilian Group Ends Military Rule", Hispanic American Historical Review", XLVII (maio, 1967), 149-1, 65. 